\title{
ANALISIS BAHAN APRON SINTETIS DENGAN FILLER TIMBAL (II) OKSIDA SESUAI SNI UNTUK PPOTEKSI RADIASI SINAR-X
}

\author{
Zaenal Abidin $^{1}$, Degesha Alkrytania ${ }^{1}$, Ihda Novia Indrajati ${ }^{2}$ \\ 1) STTN BATAN,Jl. Babarsari, Yogyakarta,Zaenala6@gmail.com \\ 1) STTN BATAN,Jl. Babarsari, Yogyakarta, degeshaalkrytania@gmail.com \\ 2) Balai Besar Kulit, Karet dan Plastik Yogyakarta, Jl., Sukonandi Yogyakarta, \\ ihdanovia@gmail.com
}

\begin{abstract}
ABSTRAK
ANALISIS BAHAN APRON SINTESIS DENGAN FILLER TIMBAL (II) OKSIDA SESUAI SNI UNTUK PROTEKSI RADIASI SINAR-X. Telah dilakukan penelitian tentang bahan apron sintetis filler timbal (II) oksida untuk proteksi radiasi sinar-X sesuai dengan peraturan kepala BAPETEN No.8 tahun 2011 yang menyebutkan bahwa apron yang disediakan di unit radiologi diagnostik intervensional harus setara dengan $0,35 \mathrm{~mm} \mathrm{~Pb}$ atau $0,5 \mathrm{~mm} \mathrm{~Pb}$. Pembuatan bahan apron sintetis berbahan dasar PVC dengan cara calendering dengan timbal (II) oksida sebagai filler dimaksudkan agar didapatkan apron yang memenuhi standar keselamatan, ringan, kuat dan nyaman digunakan serta memenuhi Standar Nasional Indonesia (SNI 1294-2009). Hasil pengujian menggunakan pesawat sinar-X Lorad LPX 200 STTN-BATAN dengan tegangan tabung sebesar $120 \mathrm{kV}$ menunjukan bahwa koefisien atenuasi sampel adalah sebesar 0,25 mm-1 dan melalui perhitungan diketahui tebal bahan apron kulit sintetis filler $\mathrm{PbO}$ yang setara dengan pelat timbal murni $\mathrm{Pb} 0,5 \mathrm{~mm}$ adalah sebesar 3,425 mm dengan daya serap sebesar $57,52 \%$ dan memenuhi pengujian kuat tarik dan kemuluran bahan sesuai SNI 1294-2009.
\end{abstract}

Kata kunci: Apron, kulit sintetis, $\mathrm{PbO}$.

\section{ABSTRACT}

ANALYSIS OF SYNTHETIC APRON FILLER LEAD (II) OXIDE OCCORDING TO INS AS AN X-RAY RADIATION PROTECTION. Determination of synthetic leather apron filler Lead Oxide material thickness as an X-Ray radiation protection in radiology unit has been done according to BAPETEN regulation number 8, 2011 which stated that aprons provided in the interventional diagnostic radiology unit must be equal to $0.3 \mathrm{~mm} P b$ or $0.5 \mathrm{~mm} \mathrm{~Pb}$. The making of PVC based synthetic leather apron material with $\mathrm{PbO}$ filler is to obtain an apron which complies with radiation safety requirement, light, durable, comfortable and complies to Indonesian National Standard (INS 1294-2009). The test result using X-Ray Lorad LPX200 STTN BATAN in $120 \mathrm{kV}$ operational voltage has shown that attenuation coeffisient $(\mu)$ is $0.25 \mathrm{~mm}^{-1}$ while the thickness of synthetic leather apron filler PbO using calculatingmethode is equal to 0.5 $\mathrm{mm} \mathrm{Pb}$ is $3.425 \mathrm{~mm}$ thick with $57.52 \%$ absorbancy and passed to the tensile strength test and material elasticity according to SNI 1294-2009.

Key words: Apron, synthetic, $\mathrm{PbO}$

\section{PENDAHULUAN}

Aplikasi teknologi nuklir merupakan suatu kemajuan dalam bidang ilmu pengetahuan dan teknologi nuklir yang pada saat ini telah banyak dimanfaatkan dalam berbagai bidang kegiatan, seperti bidang energi, industri, kedokteran, pertanian, dan arkeologi. Secara umum, aplikasi teknologi nuklir dalam bidang kedokteran dapat dibedakan menjadi 2 macam yaitu di bidang radiologi diagnostik dan intervensional.

Dalam keorganisasian rumah sakit, kedua jenis kegiatan ini diampu oleh suatu 
Unit Radiologi. Pada masing-masing bagiannya, terdapat beberapa macam spesialisasi personel yang mempunyai fungsi berbeda satu sama lain, diantaranya adalah fisikawan medis, operator alat diagnostik dan operator alat terapi. Para personel rumah sakit yang bekerja dengan radiasi beresiko menerima jumlah paparan radiasi yang lebih tinggi.

Apron adalah peralatan yang digunakan sebagai bahan pelindung terhadap radiasi sinar-X. Fungsi sebagai pelindung terhadap radiasi sinar-X ditunjukkan dengan daya serapnya terhadap radiasi sinar-X. Prinsip perisai radiasi adalah mengurangi fluks radiasi dibalik perisai. Selain mengakomodasi fungsi utama sebagai penyerap radiasi, apron proteksi radiasi harus mempunyai sifat-sifat pendukung lain seperti kuat dan nyaman saat digunakan sehingga apron tersebut layak dipakai. Sesuai dengan ketentuan pada Perka BAPETEN No 8 tahun 2011, disebutkan bahwa dalam penggunaan pesawat sinar-X radiologi diagnostik dan intervensional, pemegang izin harus menyediakan apron yang setara dengan dengan $0,2 \mathrm{~mm} \mathrm{~Pb}$, atau $0,25 \mathrm{~mm} \mathrm{~Pb}$ untuk penggunaan pesawat sinar- $\mathrm{X}$ radiologi diagnostik, dan $0,35 \mathrm{~mm} \mathrm{~Pb}$, atau $0,5 \mathrm{~mm} \mathrm{~Pb}$ untuk pesawat sinar-X radiologi intervensional. Untuk memenuhi persyaratan daya serap tersebut, material apron yang telah ada menggunakan campuran karet alam dengan timbal dan menggunakan pelat timbal murni. Apron dengan campuran karet alam masih terasa tebal, sedangkan apron dengan pelat timbal murni memiliki beberapa kekurangan yakni bentuknya yang sangat kaku, mudah tertekuk jika terjatuh, tidak dapat mengikuti bentuk tubuh sehingga kurang nyaman dipakai[ $[1,2,3]$.

Penelitian sebelumnya telah mengupayakan apron yang lebih tipis [5] dan tentang apron menggunakan timbal oksida [3]. Berikutnya telah dilakukan perhitungan tebal apron campuran karet alam yang aman yaitu setebal 2,5 $\mathrm{mm}$ yang dicampur dengan timbal oksida sebanyak 550 pphr [6], dan ketebalan lapisan tengah kulit sinstetis filler (100 pphr $\mathrm{PbO} / \mathrm{PbCl}_{2}$ ) dengan lapisan tengah $0,85 \mathrm{~mm}$ setara dengan $0,5 \mathrm{~mm} \mathrm{~Pb}$. Pada penelitian ini dilakukan perhitungan ketebalan apron dari kulit sintetis dengan pesawat sinar $\mathrm{X}$, apron dari bahan dasar PVC dengan metode calendering dan timbal (II) oksida sebagai filler dimaksudkan agar didapatkan apron yang memenuhi standar keselamatan, ringan, kuat dan nyaman dipakai serta memenuhi Standar Nasional Indonesia (SNI 12942009).[2,3,4,5,6,7]

Apron sebagai perisai radiasi digunakan untuk melemahkan intensitas radiasi (sinar-X atau gamma). Perisai tersebut harus memiliki kemampuan yang baik dalam menyerap (mengatenuasi) radiasi yang melewatinya. Setiap pancaran radiasi gamma atau sinar-X yang mengenai suatu bahan, maka akan berinteraksi dengan bahan tersebut sehingga sebagian dari intensitasnya akan terserap dan sebagian lagi akan diteruskan. Secara matematis hubungan tersebut dinyatakan dengan:

$$
\mathrm{I}=\mathrm{I}_{\mathrm{O}} \mathrm{e}^{-\mu x}
$$

dengan:

$$
\begin{aligned}
\mathrm{I}= & \text { intensitas paparan radiasi yang } \\
& \text { diteruskan (mR/jam) } \\
\mathrm{I} 0= & \text { intensitas paparan radiasi yang } \\
& \text { dating (mR/jam) } \\
\mu= & \text { koefisien serap linier bahan pada } \\
& \text { energi tertentu }\left(\mathrm{mm}^{-1}\right) \\
\mathrm{x}= & \text { tebal perisai }(\mathrm{mm})[7]
\end{aligned}
$$

Intensitas yang melewati perisai juga dapat dihitung menggunakan hubungan HVL (Half Value Layer) dengan $\mu$. [8]

$$
\mathrm{HVL}=0,693 / \mu
$$

Daya serap material perisai radiasi ditentukan berdasarkan persamaan sebagai berikut.

$$
D S=\left(1-e^{-\mu x}\right) \times 100 \%
$$

dengan:

$\mathrm{DS}=$ daya $\operatorname{serap}(\%)$

$\mu=$ koefisien atenuasi komposit, $\left(\mathrm{mm}^{-1}\right)$

$\mathrm{x}=$ tebal komposit $(\mathrm{mm})$

Nilai koefisien atenuasi $(\mu)$ bergantung pada jenis bahan radiasi dan energi dari radiasi elektromagnetik yang diserap bahan tersebut. Semakin tinggi nomor atom bahan maka nilai $\mu$ akan semakin besar, sehingga semakin baik dipakai sebagai bahan perisai untuk radiasi. Apabila unsur penyusun kedua material tersebut mempunyai nomor atom yang kurang lebih sama, maka untuk 
mencari tebal yang setara suatu material yang lain digunakan persamaan berikut[8].

$$
\sum(\rho . \mathrm{x}) \mathrm{a}=\sum(\rho . \mathrm{x}) \mathrm{b}
$$

dengan, $\rho_{a}=$ densitas, material $a, \rho b=$ densitas material $\mathrm{b}, \mathrm{x}_{\mathrm{a}}=$ tebal material $\mathrm{a}, \mathrm{xb}=$ tebal material $b$.

Salah satu bahan yang memiliki kemampuan baik dalam menyerap radiasi gamma adalah timbal. Timbal merupakan suatu unsur yang memiliki nomor atom 82 yang memiliki densitas yang cukup besar yakni sekitar $11.34 \mathrm{gr} / \mathrm{cm}^{3}$ sehingga baik untuk bahan perisai radiasi[4].

Densitas ( $\rho$ ) suatu bahan dapat dihitung melalui persamaan berikut:

$$
\rho=\text { massa/volume }
$$

\section{Timbal Oksida}

Timbal adalah suatu unsur kimia yang terdapat pada golongan IV A dan periode ke enam pada tabel periodik. Timbal memiliki koefisien serapan yang baik dan mudah didapat dipasaran dalam negeri dalam bentuk $\mathrm{PbO}$ (Timbal (II) Oksida). Timbal Oksida merupakan hasil utama yang terbentuk dalam proses memproduksi timbal, karena timbal yang ditemukan di alam tidak ditemukan bebas namun dalam bentuk biji galena $(\mathrm{PbS})$ yang mengandung $86 \% \mathrm{~Pb}$ (Timbal). Pada saat proses untuk memproduksi timbal murni, kandungan sulfide dalam biji timbal dihilangkan dengan cara memanggang biji timbal sehingga dihasilkan timbal oksida.

Timbal oksida memiliki tampilan berwarna orange dengan bentuk berupa bubuk seperti yang ditunjukkan oleh Gambar 1. Keunggulan timbal oksida adalah harganya yang murah dibandingkan timbal dalam bentuk lain seperti $\mathrm{PbCl}_{2}$ atau $\mathrm{Pb}_{3} \mathrm{O}_{4}$.

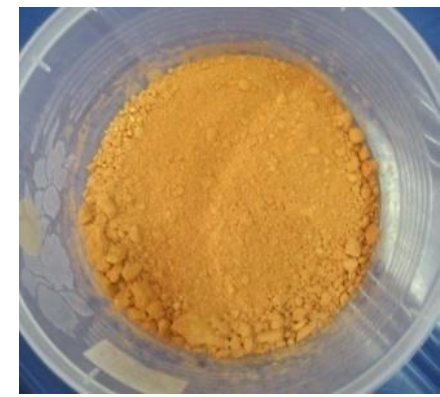

Gambar 1. Timbal (II) Oksida

\section{Kulit Sintetis}

Kulit sintetis atau kulit imitasi adalah lembaran kulit tiruan yang dibuat dari kompon polivinil klorida (PVC) atau poliuretan (PU) sebagai lapisan atasnya dan kain sebagai lapisan dasar yang berfungsi sebagai penguat, ada yang diberi busa pada lapisan tengahnya atau tanpa busa, diproses secara calendering, coating atau laminating.

Calendering adalah proses penggilasan kompon PVC atau PU lunak menggunakan mesin calender untuk membentuk lembaran plastik. Coating adalah pelapisan bahan plastik lunak pada kain penguat, dan laminating adalah penggabungan dua atau lebih lapisan plastik dengan kain penguat menggunakan lem atau panas.

Menurut struktur pelapisan terhadap kain penguat, maka kulit sintetis dapat digolongkan menjadi tiga macam, struktur pelapisan yaitu :

1. Struktur satu lapis, yaitu pelapisan kain penguat dengan satu lapis bahan polimer.

2. Struktur dua lapis, yaitu pelapisan kain penguat dengan dua pelapisan yang terdiri dari lapisan permukaan (top coat) dan lapisan dasar (base coat) dari bahan polimer.

3. Struktur tiga lapis, yaitu pelapisan kain penguat dengan tiga lapisan yang terdiri dari lapisan permukaan (top coat), lapisan tengah (middle coat) dan lapisan dasar (base coat) dari bahan polimer.

Untuk membuat bahan kulit imitasi, diperlukan bahan-bahan antara lain PVC, DOP, epoxy, stabilizer, asam stearate, filler, kickers, ADCM dan pigmen yang memiliki fungsinya masing-masing. Penelitian ini bertujuan untuk mendapatkan bahan apron alternatif yang dapat digunakan untuk proteksi radiasi.

\section{METODE}

Tahapan dalam penelitian ini yaitu:

a. Pembuatan sampel bahan apron kulit sintetis filler timbal II oksida yang dilakukan di Balai Besar Kulit, Karet dan Plastik Yogyakarta.

b. Pengukuran densitas bahan apron kulit sintetis filler timbal II oksida.

c. Pengujian koefisien atenuasi dan daya serap bahan. 
d. Perhitungan tebal HVL bahan

e. Pengujian kuat tarik dan kemuluran bahan

\section{Pembuatan Sampel bahan apron kulit sintetis filler timbal II oksida}

Sampel bahan apron kulit sintetis yang dibuat adalah kulit sintetis dengan struktur tiga lapis, dimulai dengan pembuatan lapisan atas (top coat) kemudian lapisan tengah (middle coat) dan terakhir adalah lapisan bawah (base coat) dengan variabel yang diubah adalah ketebalan pada lapisan tengah. Komposisi $\mathrm{PbO}$ sebagai filler di bagian tengah adalah sebesar $120 \mathrm{pphr}$.

\section{Pengukuran densitas bahan}

Pengukuran densitas atau massa jenis bahan dilakukan dengan menghitung volume dan massa sampel bahan apron kulit sintetis menggunakan persamaan (5).

\section{Pengujian Koefisien Atenuasi dan daya serap bahan}

Pengujian dilakukan dengan mengukur perbandingan intensitas paparan radiasi yang datang dan yang diteruskan melalui sampel bahan apron menggunakan detektor dengan pembangkit radiasi sinar- $X$ yang digunakan yaitu pesawat sinar-X lorad LPX200 STTN-BATAN dengan tegangan $(\mathrm{kV})$ sinar-X $120 \mathrm{kV}$ dan arus $5 \mathrm{~mA}$ selama 10 detik yang diatur melalui panel kontrol seperti yang ditunjukkan Gambar 2. dengan jarak bahan dari focal spot sebesar $90 \mathrm{~cm}$ seperti skema yang ditunjukkan oleh Gambar 3.

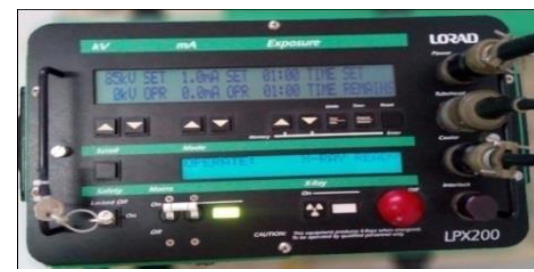

Gambar 2. Panel kontrol Lorad LPX200 STTN-BATAN

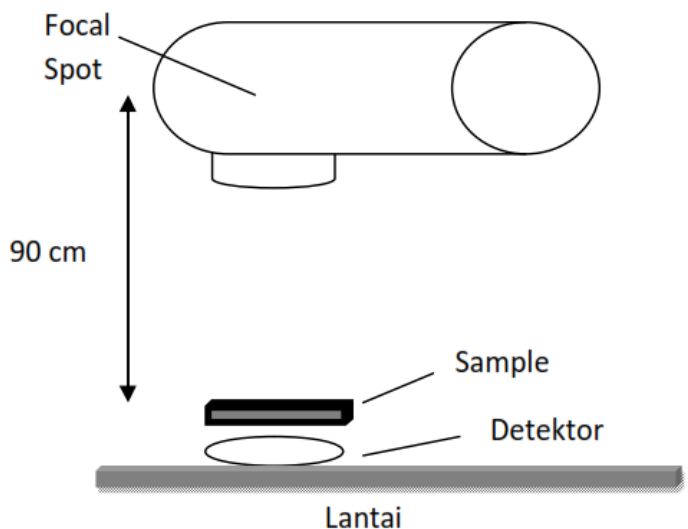

Gambar 3. Skema pengujian koefisien atenuasi terhadap radiasi sinar- $\mathrm{X}$

Kemudian dibandingan dengan
pengujian terhadap radiasi gamma menggunakan detektor Geiger Muller yang ditunjukkan Gambar 4. dengan sumber standar Cs-137 dengan energi $662 \mathrm{KeV}$ pada tegangan $900 \mathrm{~V}$ dalam waktu 60 detik dengan 30 kali pengulangan pada setiap sampel.

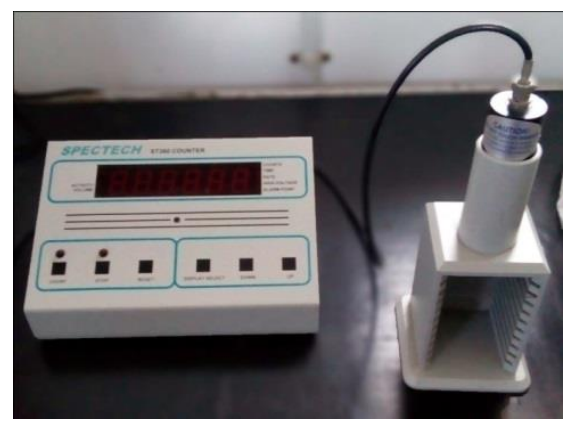

Gambar 4. Detektor Geiger Muller

Setelah dilakukan serangkaian pengujian selanjutnya data yang dihasilkan digunakan untuk menghitung koefisien atenuasi dan daya serap bahan menggunakan persamaan(3) serta HVL bahan menggunakan persamaan(2).

\section{Pengujian Kuat Tarik dan Kemuluran Bahan}

Setelah didapatkan koefisien atenuasi yang setara dengan Perka Bapeten No. 8 tahun

2011, dilakukan pengujian kuat tarik kemuluran bahan sesuai dengan Standar Nasional Indonesia nomor 1294-2009 mengenai kulit imitasi menggunakan alat uji tarik mulur dengan prinsip pengujian adalah menarik cuplikan sampai putus dengan menggunakan alat uji kuat tarik 
pada kecepatan $200 \mathrm{~mm} /$ menit untuk mengetahui apakah bahan apron kulit sintetis filler $\mathrm{PbO}$ yang dihasilkan dapat memenuhi persyaratan mutu Standar Nasional Indonesia (SNI). $[4,9,10]$

\section{HASIL DAN PEMBAHASAN}

Pembuatan bahan apron sintetis filler timbal II oksida dilakukan dengan cara calendering dengan $\mathrm{PbO}$ sebagai pengisi pada lapisan tengah kulit sintetis. Dalam penelitian ini digunakan $\mathrm{CaCO}_{3}$ sebagai filler untuk lapisan atas. Pada percobaan dengan dan tanpa $\mathrm{CaCO}_{3}$, diketahui hasil bahwa lapisan atas dengan filler memiliki struktur lapisan yang lebih padat dan kuat. Ca-Stearate digunakan sebagai pengganti stabilizer karena memiliki fungsi yang sama, yaitu menahan degradasi PVC saat dilakukan pemanasan pada suhu di atas $100^{\circ} \mathrm{C}$

Setelah didapatkan sampel bahan apron, kemudian dilakukan perhitungan massa jenis sampel bahan apron kulit sintetis filler timbal II oksida yang diukur melalui dua sampel yaitu sebesar $1,66 \mathrm{gr} / \mathrm{cm}^{3}$ dan 1,65 $\mathrm{gr} / \mathrm{cm}^{3}$. Perbedaan sebesar 0,01 tersebut disebabkan karena keberadaan $\mathrm{PbO}$ yang kurang homogen pada saat proses penggilasan (calendering). Hasil densitas bahan apron ini jauh lebih rendah dibandingkan dengan $\mathrm{Pb}$ murni yang memiliki densitas sebesar 11,34 $\mathrm{gr} / \mathrm{cm}^{3}$ dan timbal oksida $9,3 \mathrm{gr} / \mathrm{cm}^{3}$. Sehingga berat bahan apron kulit sintetis menjadi lebih rendah dan apron menjadi lebih ringan. Dalam penentuan tebal bahan apron kulit sintetis yang setara dengan pelat timbal $0,5 \mathrm{~mm}$, digunakan persamaan berat jenis bahan. Berikut adalah perhitungan ketebalan apron kulit sintetis.

$$
\begin{aligned}
& \rho_{\mathrm{a}} \times \mathrm{x}_{\mathrm{a}}=\rho \mathrm{b} \mathrm{xb}=11,34 \mathrm{gr} / \mathrm{cm}^{3} \times 0,5 \\
& \mathrm{~mm}=1,655 \mathrm{gr} / \mathrm{cm}^{3} \times \mathrm{xb} \\
& \mathrm{xb}=3,425 \mathrm{~mm}
\end{aligned}
$$

Untuk mendapatkan apron kulit sintetis yang setara dengan pelat timbal murni dengan tebal $0,5 \mathrm{~mm}$ dibutuhkan bahan apron yang memiliki ketebalan sebesar 3,425 $\mathrm{mm}$. Kemudian dari pengukuran menggunakan pesawat sinar-X dan detektor GM (Geiger Muller), diketahui bahwa koefisien atenuasi bahan terhadap sinar-X adalah sebesar $0,25 \mathrm{~mm}^{-1}$ dan terhadap sumber gamma Cs-137 adalah 0,08/mm. Dengan daya serap sebesar 23,96\%, untuk sampel terhadap sumber gamma dan $57,52 \%$ terhadap radiasi sinar-X. Berdasarkan perhitungan daya serap bahan apron kulit sintetis filler $\mathrm{PbO}$ dengan ketebalan yang setara dengan pelat timbal murni $0,5 \mathrm{~mm}$, dapat diketahui bahwa daya serap terhadap sinar gamma lebih kecil dibandingkan dengan daya serap terhadap sinar-X, hal ini disebabkan koefisien atenuasi yang berbeda. Koefisien atenuasi liniear suatu bahan tergantung pada jenis bahan dan energi sinar gamma yang mengenainya. Semakin besar energi radiasi sinar- $X$ atau sinar gamma yang mengenai suatu bahan, maka koefisien atenuasinya akan semakin kecil.

Daya serap $\mathrm{Pb}$ murni $0,5 \mathrm{~mm}$ pada tegangan 50 dan $150 \mathrm{kV}$ adalah 98,29\% dan 73,50\% [7]. Daya serap Pb murni 0,5 mm pada tegangan $100 \mathrm{kV}$ adalah 95,76\% [4]. Terhadap radiasi sinar- $X$ dengan tegangan 120 $\mathrm{kV}$, daya serap pelat timbal murni standar setebal $0,5 \mathrm{~mm}$ dihitung dengan interpolasi terhadap data daya serap $\mathrm{Pb}$ murni $0,5 \mathrm{~mm}$ pada tegangan $50 \mathrm{kV}, 100 \mathrm{kV}$ dan $150 \mathrm{kV}$. Sehingga hasil perhitungan interpolasi daya serap timbal murni $0,5 \mathrm{~mm}$ pada tegangan operasi pesawat sinar-X $120 \mathrm{kV}$ adalah sebesar $84,22 \%$. Hasil perhitungan daya serap bahan apron kulit sintetis filler $\mathrm{PbO}$ belum setara dengan daya serap pelat timbal murni standar setebal $0,5 \mathrm{~mm}$ dan memiliki selisih sebesar $26,7 \%$. Hal ini dapat disebabkan karena detektor yang digunakan terkalibrasi sebagai surveymeter gamma dan pesawat sinar-X Lorad LPX200 STTN-BATAN yang bersifat panoramik sehingga terjadi hamburan radiasi pada saat pengukuran.

Dalam pengujian kuat tarik dan kemuluran bahan apron kulit sintetis terhadap SNI 1294-2009, syarat mutu yang digunakan adalah syarat mutu tipe A karena bahan apron kulit sintetis menggunakan lapisan penguat kain rajut. Untuk kuat tarik arah melintang bahan kulit sintetis harus mampu dibebani minimal $60 \mathrm{~N}$ dan untuk arah membujur minimal $180 \mathrm{~N}$, sedangkan hasil untuk bahan apron kulit sintetis adalah 312,29 N. Untuk kuat tarik membujur dan 293,47 N untuk kuat tarik melintang. Untuk kemuluran arah membujur harus dapat mulur (20-30)\% dan arah melintang (13-20)\%, dengan hasil untuk bahan apron kulit sintetis adalah sebesar 15\% untuk kemuluran arah membujur dan $30 \%$ kemuluran arah melintang, sehingga diketahui bahwa sampel bahan apron kulit sintetis telah 
memenuhi persyaratan SNI 1294-2009 pada parameter uji kuat tarik dan kemuluran bahan.

\section{KESIMPULAN}

1. Apron sintetis berbahan dasar PVC dengan filler timbal (II) oksida dapat dibuat dengan metode calendering dengan $\mathrm{PbO}$ sebagai pengisi pada lapisan tengah.

2. Tebal bahan apron yang setara dengan pelat timbal murni dengan tebal 0,5 $\mathrm{mm}$ adalah sebesar $3,425 \mathrm{~mm}$.

3. Nilai uji kuat tarik dan kemuluran bahan apron kulit sintetis filler $\mathrm{PbO}$ memiliki hasil sebesar 312,29 N untuk kuat tarik membujur dan 293,47 N untuk kuat tarik melintang. Untuk kemuluran arah membujur adalah sebesar $15 \%$ dan $30 \%$ kemuluran arah melintang. Hasil ini telah memenuhi persyaratan SNI 1294:2009.

\section{SARAN}

1. Penelitian lebih lanjut sebaiknya apron sudah jadi kemudian digunakan pesawat sinar- $\mathrm{X}$ dengan $\mathrm{kV}$ rendah.

3. Pengujian lebih lanjut terhadap persyaratan mutu kulit sintetis dengan parameter uji yang berbeda seperti ketahanan sobek, ketahanan luntur warna, ketahanan terhadap suhu rendah dan ketahanan terhadap pengusangan.

\section{DAFTAR PUSTAKA}

1. BAPETEN. 2011. Peraturan Kepala BAPETEN Nomor 8 Tahun 2011: Keselamatan Radiasi dalam Penggunaan Pesawat Sinar-X Radiologi Diagnostik dan Intervensional. Jakarta.

2. Aji A., dkk, 2014, "Kulit Sintetis dengan Filler Timbal $\mathrm{PbCl} 2$ Sebagai Material Apron Proteksi Radiasi Gamma", Buletin Batan, ISSN 0126-3293, September, 2014, halaman 1.

3. Atmojo S.M, Irianto dan Abdul Jalil. 2007. "Rekayasa Perisai Radiasi Gamma pada Pemanfaatan Isotop ${ }^{137} \mathrm{Cs}$ dan ${ }^{60}$ Co untuk Terapi Kanker".Prosiding Pertemuan Ilmiah Nasional Rekayasa Perangkat Nuklir, Serpong.
4. Kristiyanti, dkk. 2010. Perekayasaan Perisai Radiasi Tiroid Menggunakan Komposit Lateks Cair Timbal Oksida dengan Teknologi Ultra Sonik dan Suhu Super Kritis”. Prosiding PPI-PDIPTN 2010, Yogyakarta.

5. Kristiyanti dan Sri Mulyono A. 2005. "Penentuan Daya Serap Apron dari Karet Alam Timbal Oksida Terhadap Radiasi Sinar-X". Prosiding PPI-PDIPTN, Yogyakarta.

6. Prayitno, G., 2009, Perhitungan Ketebalan Bahan Komposit Karet Alam Timbal Oksida untuk proteksi radiasi sinar X $100 \mathrm{KeV}$, Jurnal Perangkat Nuklir, 2009

7. Wardhana, Wisnu Arya, 2007. "Teknologi Nuklir Proteksi Radiasi dan Aplikasinya". Penerbit Andi. Yogyakarta.

8. Pusdiklat BATAN. 2015. Disain Penahan Ruang Sinar-X. Jakarta.

9. Standart Nasional Indonesia (SNI) 186478-2000 Apron Proteksi Radiasi sinar$\mathrm{x}$ Badan Standarisasi Nasional, Jakarta 2000

10. Standart Nasional Indonesia (SNI) 0660411999 1.embaran Vulkanisasi Karel Timbal untuk Perisai Sinar-X. Badan Standarisasi Nasional, Jakarta 1999.

11. Standart Nasional Indonesia (SNI) 186479-2000 : Pakaian Proteksi Sinar-X untuk Pasien, Badan Standarisasi Nasional, Jakarta 2000

12. Standart Nasional Indonesia (SNI) 186480-2000 Metode Pengujian Ekivalen Timbal untuk Peratatan Sinar-X. Badan Standarisasi Nasional, Jakarta 2000. 